\title{
DISPLACED FRACTURES OF THE LATERAL HUMERAL CONDYLE IN CHILDREN
}

\author{
Alan N. Conner and M. G. H. Smith, Glasgow, Scotland \\ From the Royal Hospital for Sick Children, Glasgow
}

Fracture of the lateral humeral condyle is a relatively common injury in children. In the displaced type most authors advise open reduction and internal fixation, although Kini (1942) and McLearie and Merson (1954) reported good results by closed manipulation. Controversy still exists as to whether the fixation should be by soft-tissue suture (Badger 1954, Crabbe 1963) or by pin or screw (Wilson 1955, Jeffery 1958). It is the purpose of this paper to review a series of fractures of the lateral humeral condyle in children which were treated by a specially designed screw. The mechanism of injury and the indications for internal fixation are discussed.

\section{CLINICAL MATERIAL}

In the eight years from 1961 to 1968 thirty-nine children with displaced fractures of the lateral humeral condyle attended the Royal Hospital for Sick Children, Glasgow. There were thirty-four boys and five girls with an average age of six years. The youngest was aged three and the oldest ten years. In thirty-one cases the injury was to the left elbow. All except two were caused by a fall on the outstretched hand.

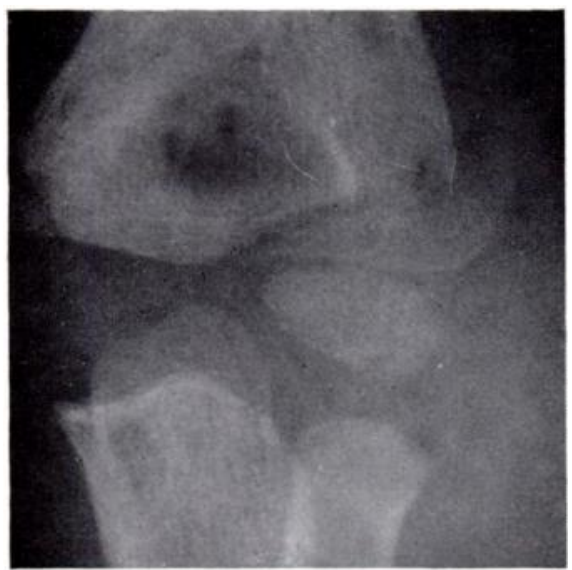

FiG. 1

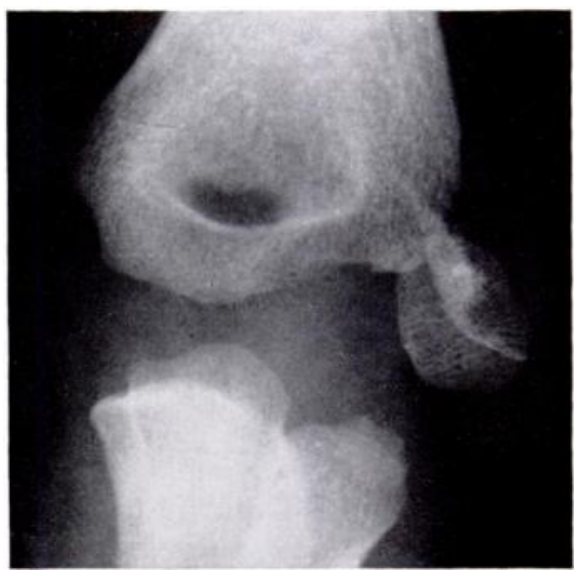

FiG. 2

Figure 1-A fracture of the lateral humeral condyle with slight displacement. Figure 2-A fracture of the lateral humeral condyle with severe displacement. The metaphysial fragment is no more than a flake in this instance.

The degree of displacement was classified as slight or severe (Figs. 1 and 2). All but three were severely displaced. The size of the metaphysial fragment varied but in only three cases could it be described as a flake (Fig. 2).

The shadow of soft-tissue swelling on the lateral side of the elbow was a constant finding on the initial radiographs. In ten children there was similar swelling on the medial side, suggesting more extensive soft-tissue injury.

Five elbows were dislocated postero-laterally at the time of admission to hospital. Recently we have made a point of examining the elbow for instability when the child has been anaesthetised and, of ten elbows examined, eight dislocated easily. Careful review of the 
initial radiographs of these eight children showed that in two of them there was lateral humeroulnar subluxation, but in the other six the joints were congruous.

\section{MANAGEMENT}

Internal fixation was used in all. Because of the difficulty in fixing the fragment to the soft cancellous bone of the lower humerus a special 2.5-centimetre coarse-threaded screw devised by Mr N. J. Blockey, and made by the London Splint Company as the "Glasgow" screw, was used (Figs. 3 and 4).

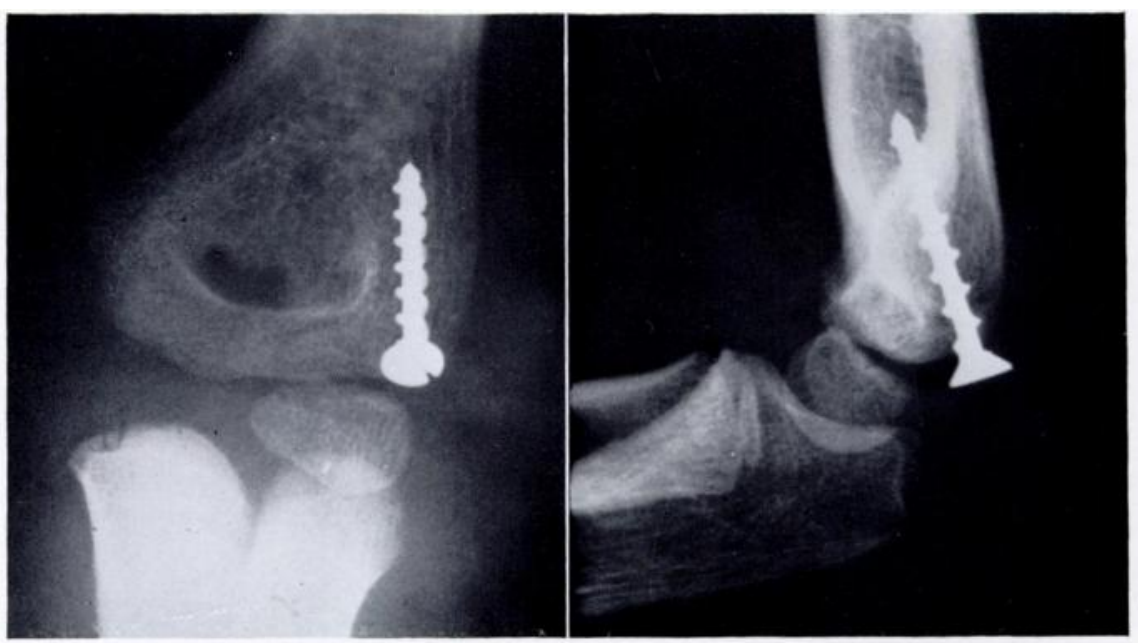

FIG. 3

The screw inserted. It engages only the metaphysial part of the condylar fragment.

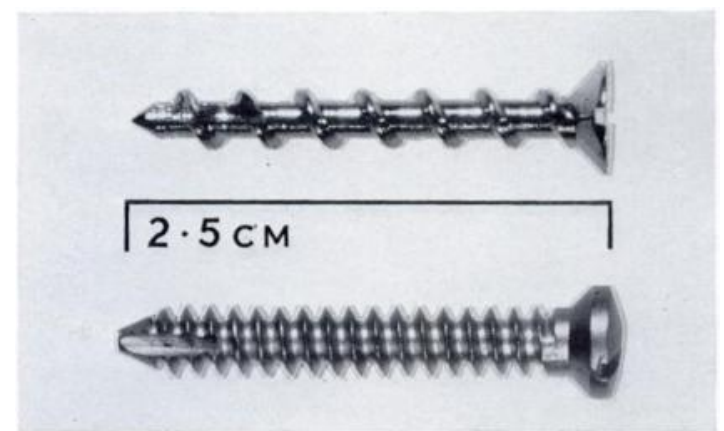

Fig. 4

The "Glasgow" screw. A standard screw of the same length ( 2.5 centimetres) is shown to emphasise the coarse thread of the "Glasgow" screw.

The technique of insertion is simple. Under tourniquet an incision five to seven centimetres long is made, centred over the lateral humeral condyle. The wound is deepened to the common extensor origin to reveal the fracture haematoma and displaced distal fragment. This may be difficult to replace until dislocation of the elbow has been allowed to occur as a temporary measure. The fragment is then held with a towel clip while a hole is drilled through its metaphysial corner. It is not necessary to drill the proximal fragment because the screw easily cuts its own track. The screw should not intrude on the epiphysial plate or the articular surface (Fig. 3). After closure of the wound the arm is immobilised for three weeks in a plaster from the axilla to the wrist with the elbow at 90 degrees. Active exercises are then encouraged.

vol. 52 B, No. 3, AUGUST 1970 


\section{RESUI.TS}

Thirty-five children attended for review and were assessed clinically and radiologically. The average follow-up was three years, the least being one year.

There was one case of established non-union. The other fractures united without delay, although two of them had been incompletely reduced and a third was not rigidly fixed by the screw. In two children the screw crossed the epiphysial plate but there was no evidence of growth arrest.

Full elbow movement was regained in twenty-six children. The other nine had full flexion but some restriction of extension. In six of the latter the loss was less than 5 degrees. In the remaining three children the loss was greater; the one with non-union lost 10 degrees; the one with the shortest follow-up of twelve months lost 15 degrees; and the one with malunion lost 25 degrees.

\section{COMPLICATIONS}

In eight children the screw head was prominent and tender necessitating removal of the screw. In a further five it had backed out and was loose: in two of these a bursa had formed over the screw head.

Late sequelae were rare. Cubitus valgus of less than 5 degrees occurred in two children. Cubitus varus of 5 degrees was seen in one child who had sustained a supracondylar fracture of the humerus a year before the injury to the lateral condyle.

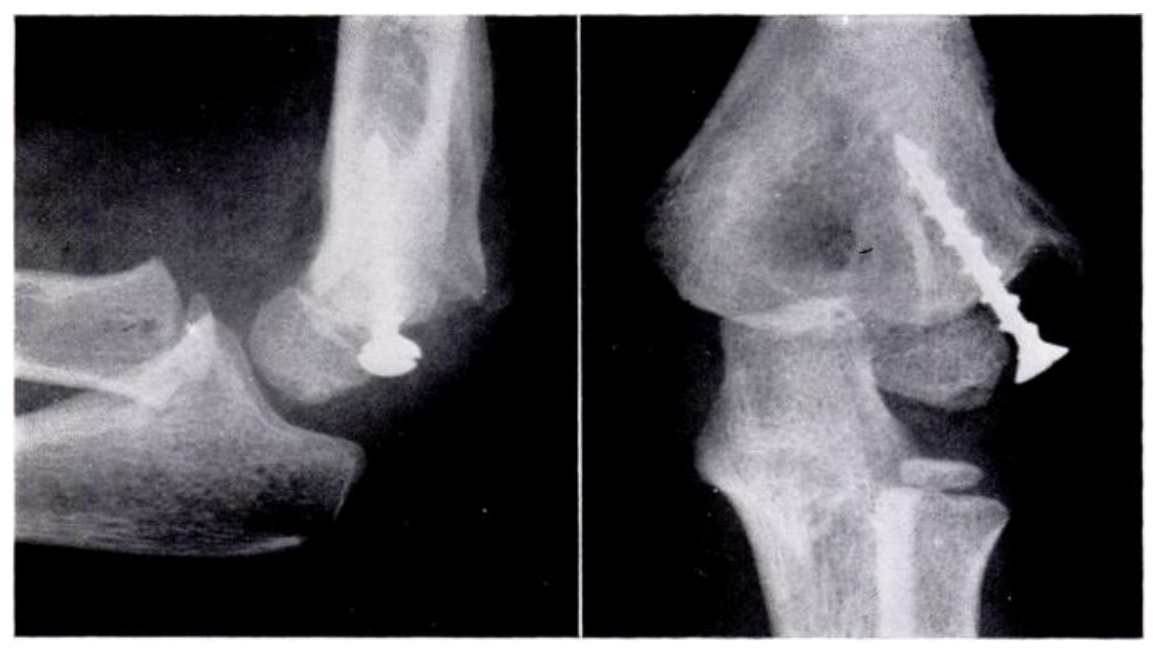

FIG. 5

Postero-lateral spur formation one year after internal fixation of a fracture of the lateral humeral condyle.

In twenty-three cases a bony spur was noted on the posterior aspect of the lateral condyle (Fig. 5). This often made a palpable prominence that could be mistaken for the screw head. A spur has also been observed after fractures treated conservatively.

\section{DISCUSSION}

The results in this series of displaced fractures compare favourably with those reported by other authors (Kini 1942. Crabbe 1963). Screw fixation is simple to perform but the choice of screw is important: the usual fine-threaded bone screw is not suitable for the cancellous bone of the lower humerus. The coarse thread of the "Glasgow" screw grips well and enters the bone easily without drilling. 
Although we did not find the development of premature epiphysial fusion as described by Wadsworth (1964), the occurrence of mild valgus deformities in two children suggests that some interference with epiphysial growth took place.

While it is recommended that all displaced fractures should be treated by internal fixation those with little displacement are usually treated conservatively. Jeffery (1958) showed that some fractures in this latter group are unstable and may not unite. We have recently seen two examples of this in which the lateral condyle migrated laterally with resultant non-union (Figs. 6 to 8). Such injuries can be expected to lead to severe cubitus valgus and tardy ulnar palsy (Fig. 9).

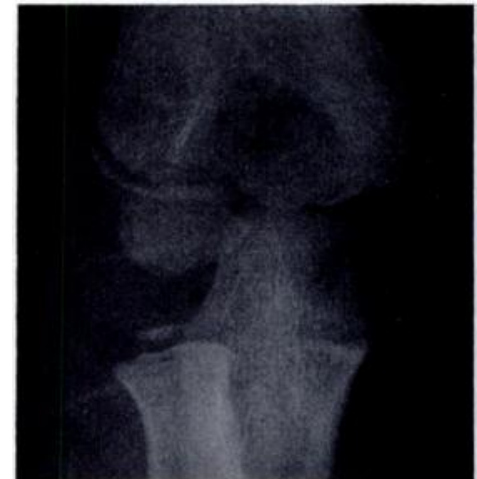

FIG. 6

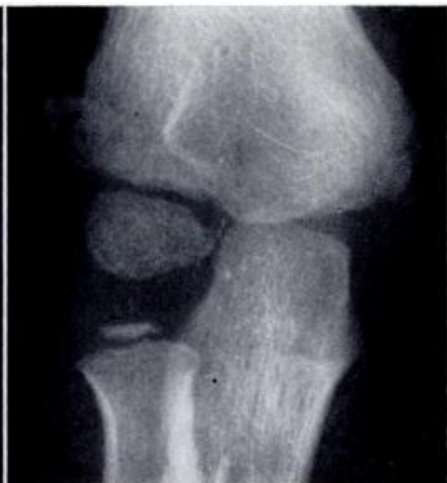

FIG. 7

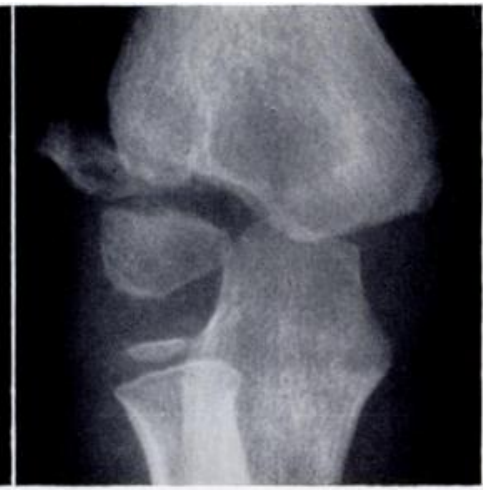

FIG. 8

Fracture of the lateral condyle of the humerus, initially with slight displacement (Fig. 6). This was treated conservatively and union failed to occur. Progressive lateral migration of the fragment at one month (Fig. 7) and at three months (Fig. 8) is shown.

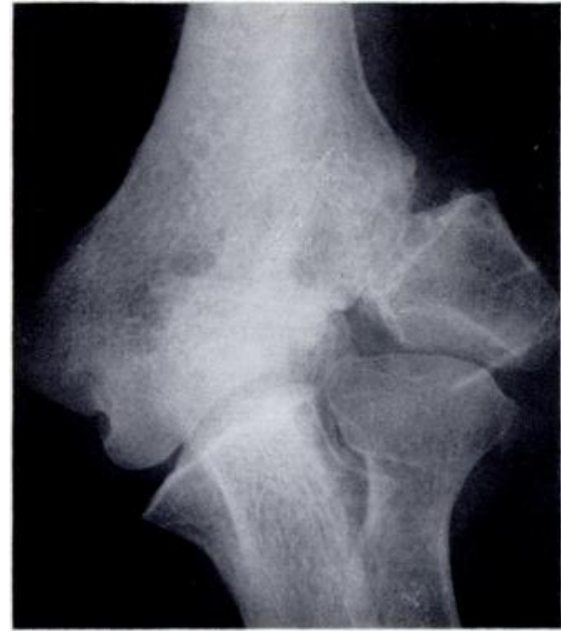

Fig. 9

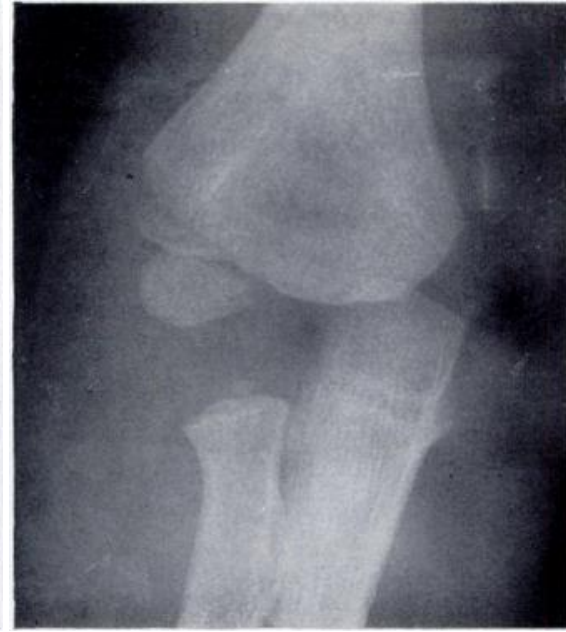

FIG. 10

Figure 9-Radiograph of a middle-aged patient with cubitus valgus and tardy ulnar palsy. In childhood there had been a fracture of the lateral humeral condyle which failed to unite. Figure 10-Radiograph showing lateral humero-ulnar subluxation associated with an unstable fracture of the lateral condyle.

There is evidence from McLearie and Merson (1954) and from our own series that many fractures of the lateral humeral condyle are associated with postero-lateral dislocation of the elbow joint, and that spontaneous reduction of the dislocation often occurs before the child is examined in hospital. The fracture may then be unstable, and this should be suspected if there is much soft-tissue swelling over the lateral side of the elbow or if humero-ulnar subluxation is seen on the initial radiograph (Fig. 10). We recommend that such elbows be examined 
under anaesthesia for instability. If this is confirmed the fracture should be fixed internally irrespective of the initial radiograph or of the reduction obtained by manipulation.

\section{SUMMARY}

1. Thirty-nine displaced fractures of the lateral humeral condyle in children are reported. In one-third of the children the injury was accompanied by postero-lateral dislocation of the elbow. In some cases there was evidence that dislocation had occurred even when there was little persistent displacement of the condylar fragment.

2. All the fractures were treated by internal fixation with a specially designed screw. Thirtyfive children attended for review.

3. It is concluded that all displaced fractures should be treated by internal fixation and that the method described is simple and reliable. Undisplaced fractures, or those with little displacement, may be treated conservatively when there is no evidence of associated dislocation of the elbow.

We wish to thank Mr N. J. Blockey and Mr D. A. Macpherson for access to their patients.

\section{REFERENCES}

BAdger, F. G. (1954): Fractures of the Lateral Condyle of the Humerus. Journal of Bone and Joint Surgery, 36-B, 147.

Crabbe, W. A. (1963): The Treatment of Fracture-separation of the Capitular Epiphysis. Journal of Bone and Joint Surgery, 45-B, 722.

JEFFERY, C. C. (1958): Non-union of the Epiphysis of the Lateral Condyle of the Humerus. Journal of Bone and Joint Surgery, 40-B, 396.

KINI, M. G. (1942): Fractures of the Lateral Condyle of the Lower End of the Humerus with Complications. Journal of Bone and Joint Surgery, 24, 270.

MCLearie, M., and Merson, R. D. (1954): Injuries to the Lateral Condyle Epiphysis of the Humerus in Children. Journal of Bone and Joint Surgery, 36-B, 84.

Wadsworth, T. G. (1964): Premature Epiphysial Fusion after Injury of the Capitulum. Journal of Bone and Joi:t Surgery, 46-B, 46.

WILSON, J. N. (1955): Fractures of the External Condyle of the Humerus in Children. British Journal of Surgery, 43, 88. 